\title{
Bilateral interdigital pilonidal sinus of the hand in a male hairdresser
}

\author{
Abdullah Örs, $\mathrm{MD}^{1}$ (D), Birkan Kibar, $\mathrm{MD}^{2} \mathbb{D}$ \\ ${ }^{1}$ Department of Anatomy, Kocaeli University Faculty of Medicine, Kocaeli, Turkey \\ 2Department of Orthopedics and Traumatology, Haydarpaşa Numune Training and Research Hospital, Istanbul, Turkey
}

\begin{abstract}
A 29-year-old, right-handed male barber was referred to our outpatient department with bilateral chronic sinus of the hand on the second web for one and a half years. He had no past and family history, was not taking any medication, and did not suffer from any other skin disease. He was working as a male barber for eight years. He had four previous recurrent attacks of infection and was prescribed oral antibiotics. Although his complaints regressed, they appeared again over time. At the time of his admission to our outpatient clinic, there were bilateral external openings on the second webs; a fluid with an unpleasant odor was issuing from these openings, and there was an erythematous and ulcerative lesion in the middle of the dorsal side of the middle finger's metacarpophalangeal joint of the left hand (Figure 1). Palpation of the interdigital fold caused the discharge of seropurulent fluid. The white blood cell (WBC) count was $8.83 \times 10^{9} / \mathrm{L}$ with a C-reactive protein (CRP) of $1.6 \mathrm{mg} / \mathrm{dL}$ and an erythrocyte sedimentation rate (ESR) of $16 \mathrm{~mm} / \mathrm{h}$ in the blood test. Plain radiography
\end{abstract}

Received: May 01, 2021

Accepted: May 25, 2021

Published online: June 11, 2021

Correspondence: Abdullah Örs, MD. Kocaeli Üniversitesi Tıp Fakültesi Anatomi Anabilim Dalı, 41001 Umuttepe, Kocaeli, Türkiye.

E-mail: abdullah.ors@kocaeli.edu.tr

Doi: $10.52312 /$ jdrs.2021.263

Citation: Örs A, Kibar B. Bilateral interdigital pilonidal sinus of the hand in a male hairdresser. Jt Dis Relat Surg 2021;32(2):523-525.

(02021 All right reserved by the Turkish Joint Diseases Foundation

This is an open access article under the terms of the Creative Commons Attribution-NonCommercial License, which permits use, distribution and reproduction in any medium, provided the original work is properly cited and is not used for commercial purposes (http://creativecommons.org/licenses/by-nc/4.0/). showed a slight radiolucency in the soft tissue without osteomyelitis. Surgical treatment was decided, and a written informed consent was obtained.

The patient was operated on under general anesthesia. Bilateral second web zig-zag incisions were made. Both the sinuses had an external opening on the second web. The sinus and fistula tracts were totally excised, the chronic inflammatory tissue around the sinus tracts was also excised, and debridement, curettage and irrigation were performed. The samples were sent for pathology and culture. In addition, the ulcerative tissue in the left hand was excised, and the surgical defect was closed primarily. When the fistula tract was opened, there were multiple hairs in it (Figure 2). Staphylococcus aureus was proliferated in the culture taken from the ulcerative lesion on the left hand. Oral trimethoprim/sulfamethoxazole 800/160 mg was given twice a day for two weeks. According to the pathology report, there was a significant increase in the fibrocollagenous connective tissue, and a foreign body giant cell reaction developed against the hair shaft with granulation tissue containing acute and chronic inflammatory cells; the sinus tracts were surrounded by squamous epithelium with no hair follicles.

Immediately after the excision and drainage, the patient's complaints improved. The wound healed smoothly within the first week, and the sutures were removed after three weeks. The patient used open-ended protective gloves (to retain pulp sensitivity); no recurrence occurred at his four-year follow-up, and he is still working as a barber (Figure 3).

Pilonidal sinus of the interdigital web space of the hand is a rare occupational disease that occurs in hairdressers. It is caused by short hairs penetrating 


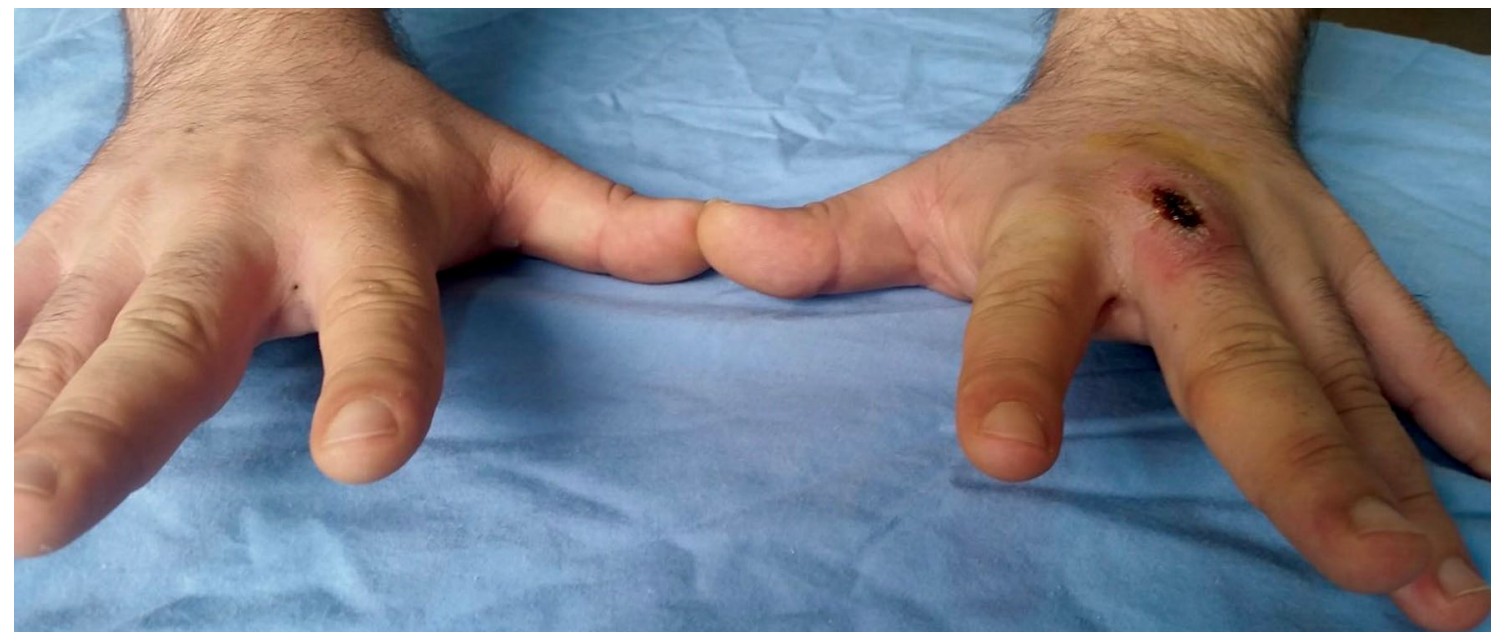

FIGURE 1. Image of bilateral pilonidal sinus at the second web showing external openings and there is an ulcerative lesion in dorsal side of the left middle finger.
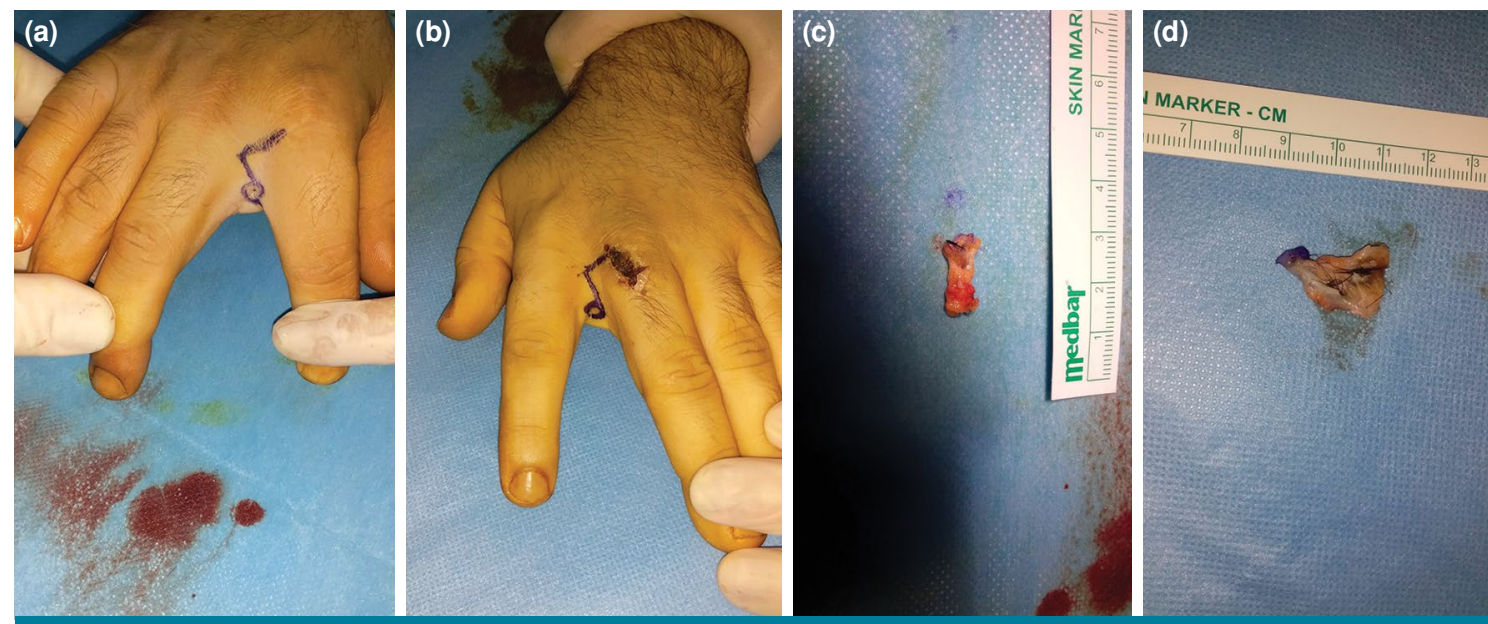

FIGURE 2. (a, b) Determining the incision line, (c) the excised cyst, (d) when the sinus tract is opened, multiple hairs are seen.

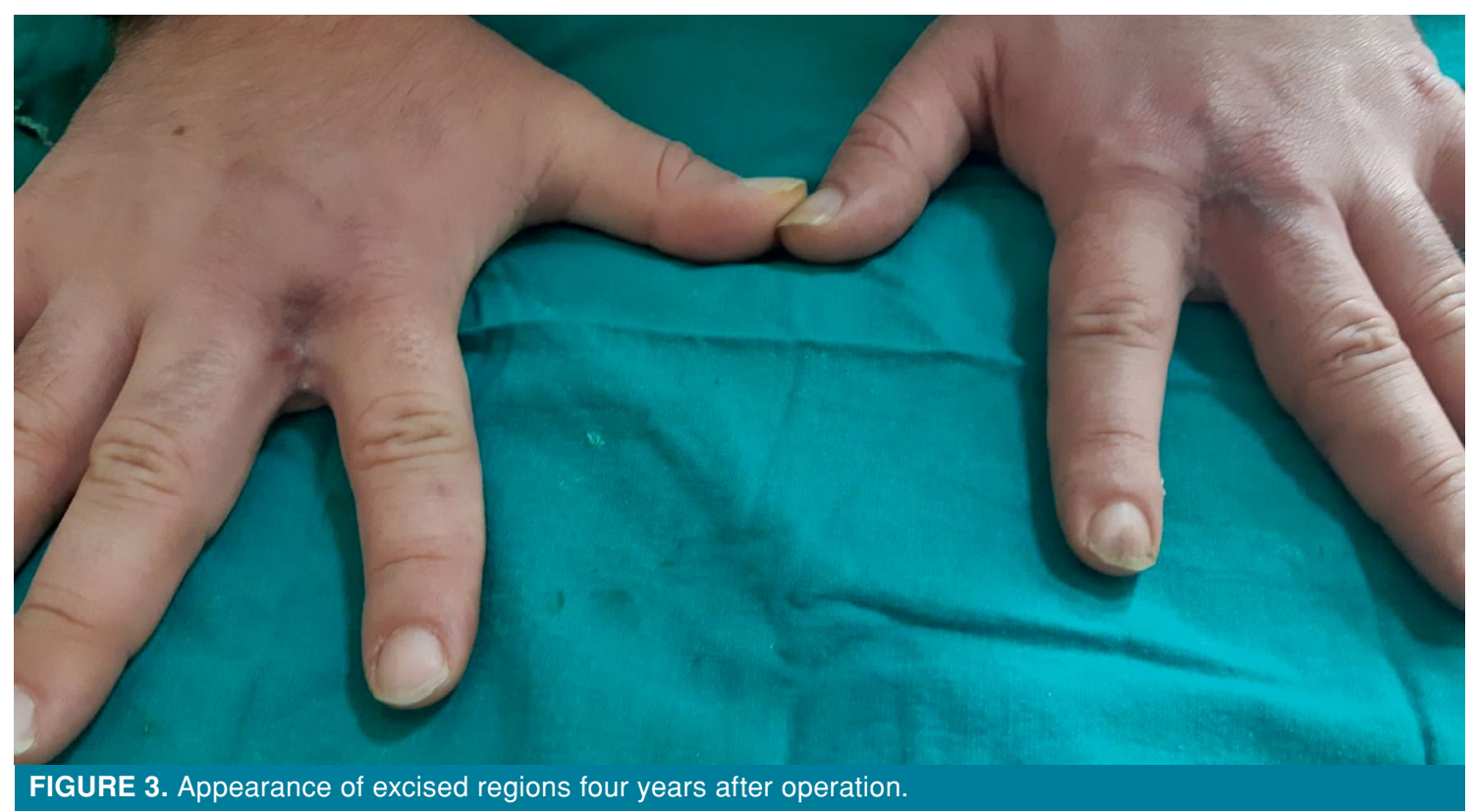


the interdigital spaces of the hand. Short cut hair is sharp like a needle, electrostatic, and adhesive and can perforate the epidermis. With the penetration of the hair into the skin, a foreign body reaction develops, and a sinus occurs with the ongoing chronic inflammatory process. The sinus, then, allows more hair to enter the skin, causing cyst formation. Surgical excision and healing by secondary intention, direct closure, and graft or flap closure can be applied in the treatment. Complications include local cellulitis, abscess formation, purulent discharge, lymphangitis, and, rarely, osteomyelitis.

Barbers' hair sinus often develops in the web space as the cut hair accumulates there, particularly in the non-dominant hair-holding hand. However, as confirmed by our case, hair sinuses developed bilaterally. We believe that surgical excision and primary closure we apply in the treatment of barbers' hair sinus is an effective method, and we recommend this technique with the advantage of rapid wound healing and a less obvious scar.

\section{Declaration of conflicting interests}

The authors declared no conflicts of interest with respect to the authorship and/or publication of this article.

\section{Funding}

The authors received no financial support for the research and/or authorship of this article. 